\title{
Schilder's disease (sudanophilic leucodystrophy) in five male members of one family
}

\author{
L. CROME ${ }^{1}$ AND M. ZA
}

From the Fountain Hospital, London

Five instances of Schilder's disease have occurred in one unfortunate English family. Three of these have been recorded already. In Fig. 1 case III 2 is case 1 of Stewart, Greenfield, and Blandy (1927), who died in 1922, aged 8 years, after an illness lasting 12 months. Case III 6 is the case of Meyer and Pilkington (1936) who died in 1934, aged 11 years, after four years of illness. The third recorded case is IV 2 who died in 1958, aged 12, after an illness lasting about five years. This case was presented at the Seventh International Congress of Neurology in Rome by Norman (1961). The object of this report is to bring the history of this family up to date with the description of the two remaining cases, and to consider certain implications of the data.

CASE 1 (IV 7)

This boy was born, after a normal confinement, weighing $3.5 \mathrm{~kg}$. He sat up at 1 year and walked at 16 months but speech was apparently delayed till 4 years. At 8 years he became irritable and his personality changed. He was seen at Queen Mary's Hospital for Children and found

'Part of the histological work was done with the aid of a grant by the Mental Health Research Fund. to be mildly mentally retarded, without sensory or motor dysfunction. An E.E.G. was thought to be compatible with the diagnosis of petit mal, although no clinical epilepsy was observed at the time. At 10 years he became incontinent of urine and faeces and required spoon feeding. He was often awake at night crying and moaning continuously. Petit mal attacks commenced at that time. When 11 years old he was admitted to hospital. He was then disorientated and uncooperative, lying in bed with both knees drawn up. Muscle tone was increased moderately in both arms, and markedly in the legs, so that the right leg could not be extended beyond $90^{\circ}$. There was marked wasting of the small muscles of both hands. He had bilateral ankle clonus and increased tendon jerks with upgoing toes.

He died from pneumonia two weeks after admission.

\section{PATHOLOGICAL FINDINGS IN CASE 1}

The brain was normal in size $(1,483 \mathrm{~g}$.) and presented no abnormality on external examination other than slight flattening of the convolutions. All cranial nerves and basal vessels seemed normal. When cut into coronal blocks, a continuous irregularly shaped area of degeneration was seen in both hemispheres. It commenced anteriorly in the centre

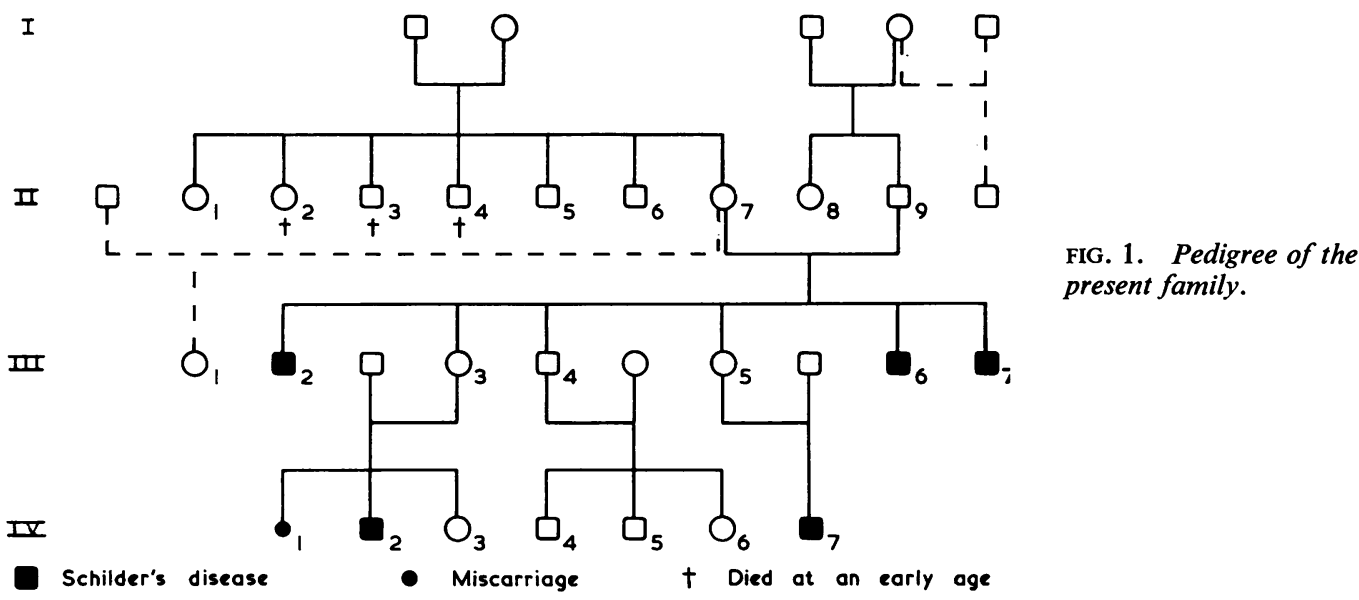


of the white matter about $2 \mathrm{~cm}$. behind the frontal poles, and enlarged rapidly to affect almost half of the centrum semiovale at the level of the anterior portion of the lateral ventricles. In the basal ganglia the lesion was restricted mainly to grey matter with relatively slight involvement of the contiguous white matter. Both the striate body and thalamus were affected as well as the internal and external capsules. Posteriorly, the lesions ended at the level of the splenium of the corpus callosum. The optic tracts showed an area of discoloration, but the optic radiations and the occipital lobes seemed intact. The affected areas were discoloured, soft, slightly granular, and showed commencing focal breakdown. The appearance varied from area to area, suggesting unequal duration or intensity of the process. The brain-stem and spinal cord were normal, but the cerebellum presented bilateral symmetrical lesions, affecting the dentate nuclei and extending into the surrounding white matter.

After prolonged fixation in formalin many blocks of representative levels of the central nervous system were embedded in paraffin and in celloidin and stained by the usual general and neuropathological methods.

Large demyelinated areas in both hemispheres involved the inferior half of the centrum semiovale (Fig. 2), the claustrum, the capsula externa, the anterior part of the striatum, the capsula interna, the nucleus anterior, nucleus medialis and the inferior part of the nucleus lateralis of the thalamus, the geniculo-calcarine tract, and the dorsal aspect of the optic tracts (Fig. 3). The demyelinated areas were continuous with that of the other hemisphere through the inferior half of the corpus callosum. A considerable part of the rostrum of the fimbria was also involved. The margins of the lesions were everywhere sharply outlined. The subarcuate fibres of the white matter were mostly spared. Within the demyelinated zone there was almost complete absence of myelin fibres and of axis cylinders. Only at the margin of the lesion were the axis cylinders slightly better preserved than the myelin sheaths. Some of the affected thalamic areas showed somewhat better preservation of myelin, indicating, possibly, a shorter duration of the pathological process. Most of the blood vessels at the periphery of the lesion were cuffed by thick sleeves of mononuclear cells, some of which were lymphocytes and plasma cells, and these were often surrounded by a few layers of fat-laden phagocytes (Fig. 4). Towards the central parts of the demyelinating area perivascular cuffing became less evident, some blood vessels showing only a single peripheral ring of fatladen cells. The affected white matter showed a varying degree of fibrous gliosis. In general, this was most marked at the periphery of the lesions. $Z$ Many astrocytes with an increased number of $\stackrel{\mathbb{D}}{\leftarrow}$ fibrillary branches were also present at the margins o of the lesion. Towards the centre, these cells became less numerous, more swollen-bodied, and had 0 fewer fibrillary processes. Many other swollen-bodied on cells presented eccentrically placed nuclei, while $\frac{\rho}{\zeta}$ there were also multinucleate cells with thin, elongated nuclei situated beneath the surface $\stackrel{\gtrless}{\gtrless}$ membranes. Some of these were indistinguishable $\vec{F}$ from so-called epithelioid and globoid cells, allegedly $\stackrel{5}{\rightarrow}$ characteristic for Krabbe's form of leucodystrophy (Fig. 5). Sudan stains displayed many brick- 음 coloured granules, forming a particularly dense zone at the margin of the lesions. Most of the $\stackrel{\triangleright}{\propto}$ sudanophil material was contained within com- ® pound granular corpuscles. These were very numerous at the periphery of the lesions decreasing gradually towards its centre, where they were present only in the perivascular sleeves. The phagocytic cells and the smaller astrocytes contained some P.A.S.-positive material, but no metachromasia was demonstrable with thionine or cresyl violet. Recognizable oligodendroglial cells were scarce and mosto of these were swollen. None was identifiable in the $\overrightarrow{\underline{\omega}}$ centre of the lesion.

Besides the main demyelinating area, there were two other, smaller foci. One of these, in the right cingulum, measured only a few millimetres in diameter. Its margins were sharp and it was histo logically identical with the main demyelinated area The other area was situated in the dorsal part of the rostrum of the corpus callosum. Pallor of myelin was also present in the central part of the white matter of the temporal and occipital lobes, and the latter showed some degeneration of myelin fibres. The neurones in the deeper layers showed peripheral chromatolysis and cytoplasmic swelling. Proliferation of fibrous astrocytes was present in layer VI.

Many nerve cells in the thalamus had disappeared, others were shrunken or showed cytoplasmic swelling and loss of Nissl granules. Severe secondary demyelination was present in the bases of the peduncles, pons, and pyramids (Fig. 3). The spinocerebellar tracts also showed some myelin loss. The medial longitudinal fasciculi, the medial lemnisci, the tectospinal tracts, and olivocerebellar fibres were spared. As mentioned already two large demyelinated areas were present in the cerebellar hemispheres (Fig. 6). They were histologically identical with the main lesion in the cerebral hemispheres. The cerebellar cortex was normal.

The only significant extraneural findings were lobar pneumonia with fibrinous pleurisy, and small adrenals.

The neurochemical findings are given in Table I. 


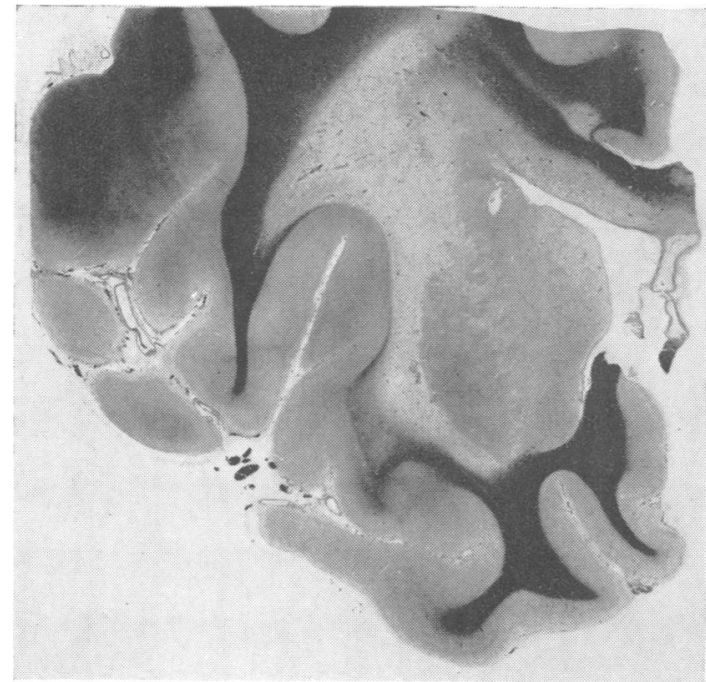

FIG. 2. Coronal section at head of caudate nucleus. Demyelination of the greater part of centrum semiovale, inferior aspect of corpus callosum, and basal ganglia. Heidenhain $\times 2.5$.

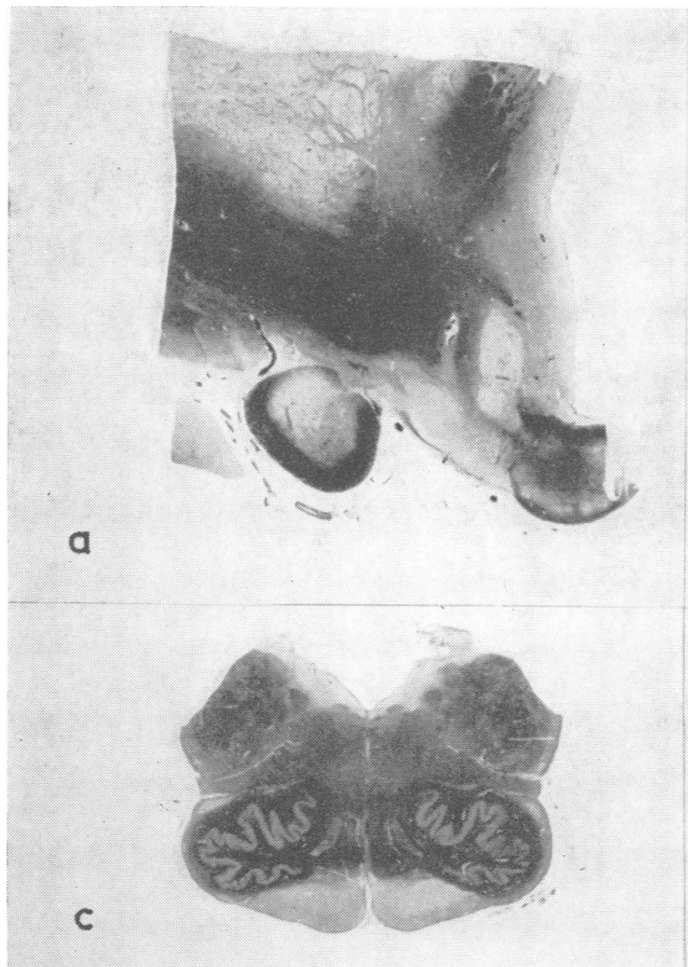

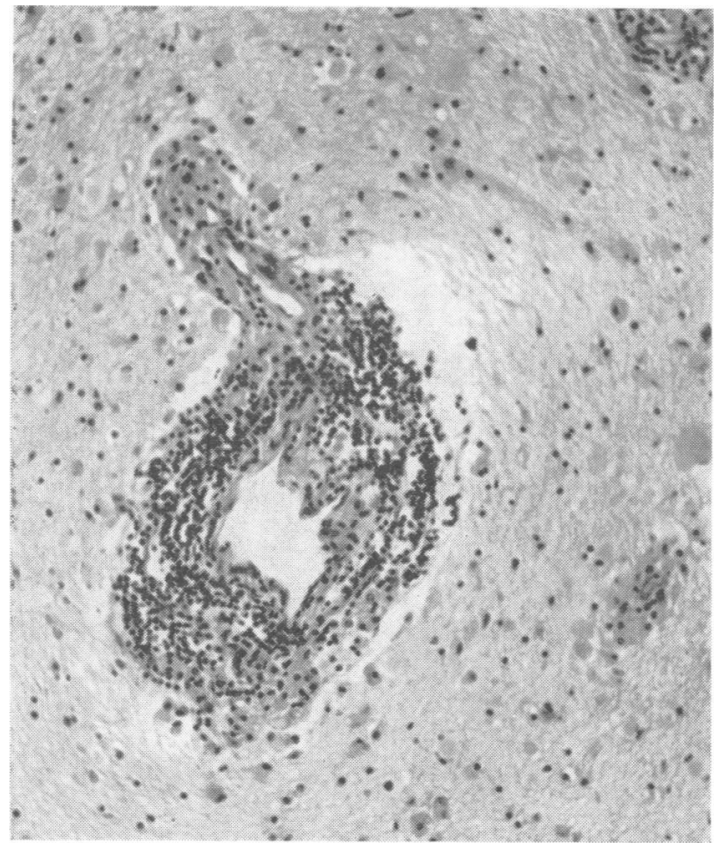

FIG. 4. Perivascular cuffing in the demyelinated area. Heidenhain-van Gieson $\times 150$.

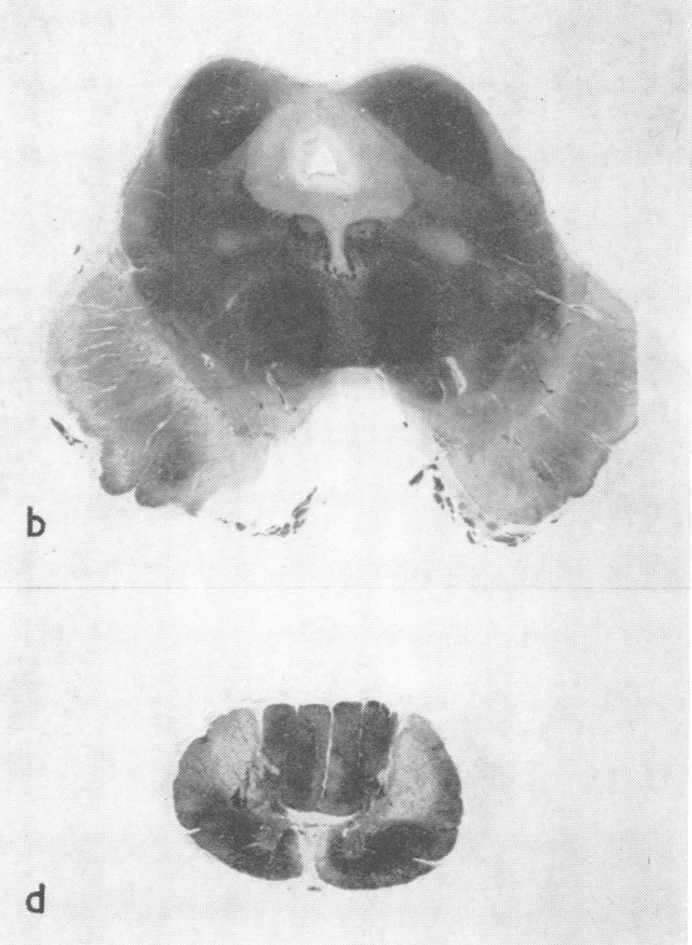

FIG. 3. a Demyelination of optic tract. Heidenhain $\times 4$. b Atrophy of the bases of the cerebral peduncles. c Atrophy of pyramids. Heidenhain $\times 4 . \mathrm{d}$ Atrophy of cortico-spinal tracts in the lateral and anterior columns of the spinal cord. Heidenhain $\times 4$. 

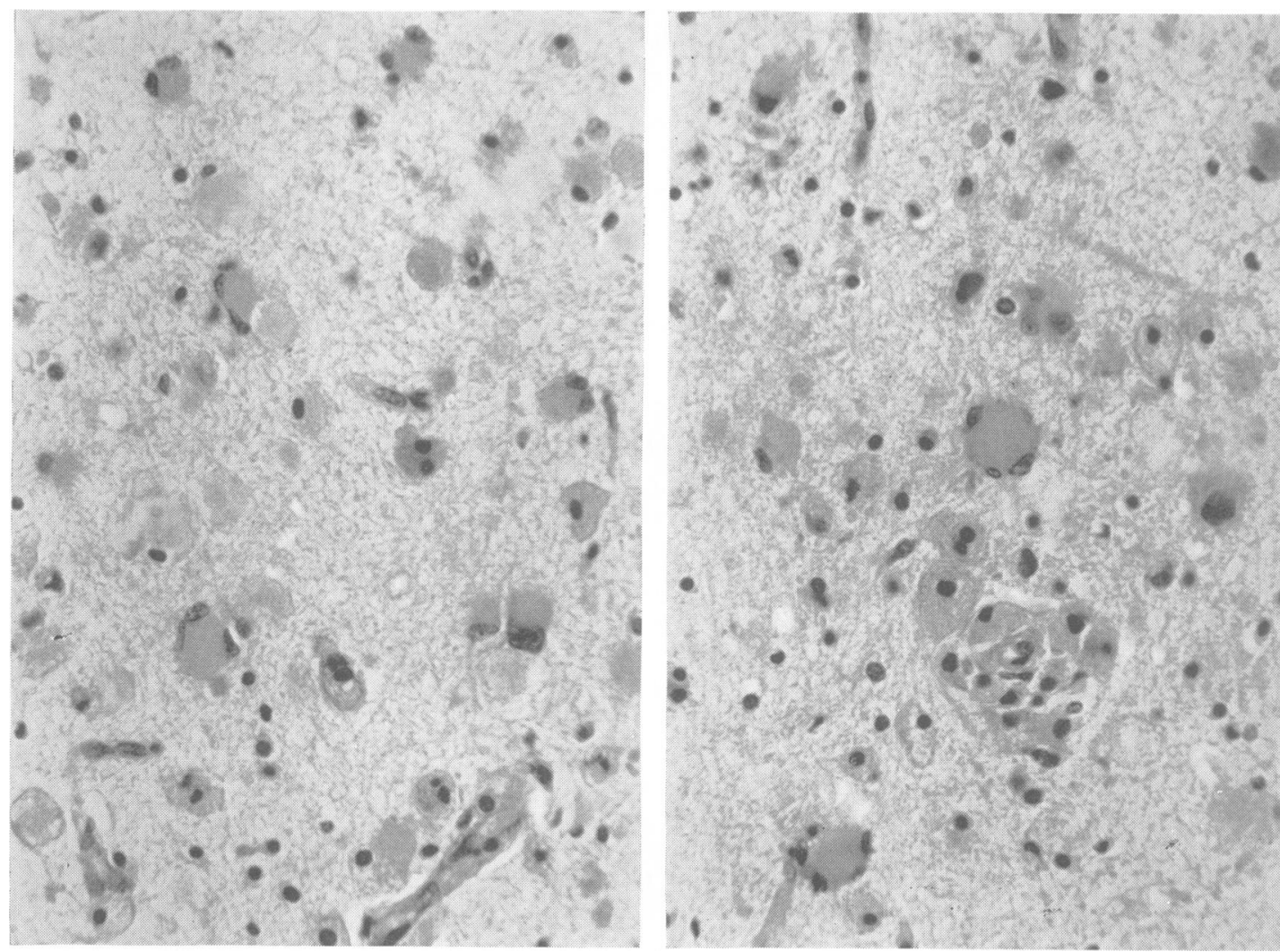

FIG. 5. 'Epithelioid' cells around a capillary and a few globoid cells in two demyelinated areas. Heidenhain-vain ç Gieson $\times 385$.

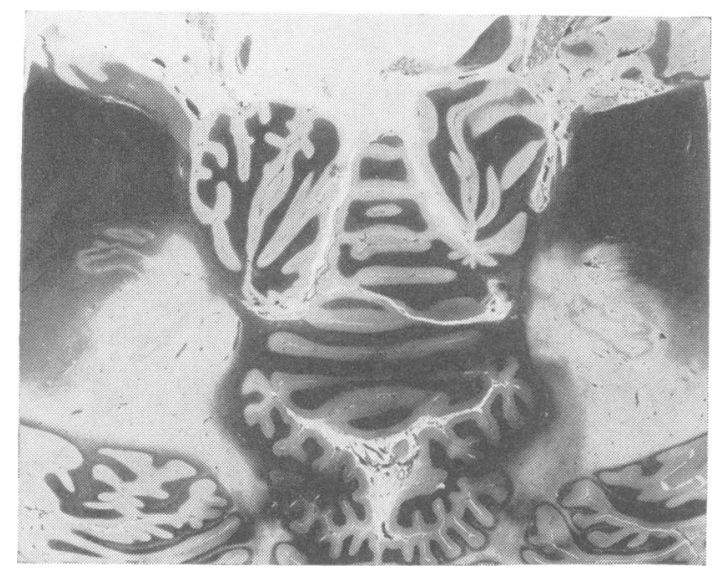

FIG. 6. Bilateral demyelination of the cerebellum. Heidenhain $\times 3$.
TABLE I

CONTENT OF BRAIN IN g./100 g. DRY TISSUE WITH APPROXIMATE FOR NORMAL IN PARENTHESES (CUMINGS, 1962)

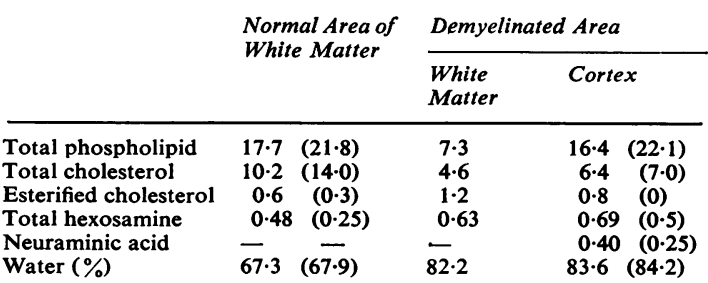

They show considerable loss of phospholipids and a very definite and marked increase of esterified cholesterol as well as some increase of total hexosamine in the demyelinated area. These findings are in keeping with sudanophilic leucodystrophy. 
CASE 2 (III, 7)

The mother suffered from unspecified bad health during pregnancy in 1926. The patient was frail, and suffered from vague gastric disorders from 4 to 6 years of age. At 7 years his mother noticed a personality change suggestive of mental deterioration. He was then attending an elementary school, but at 8 years his condition deteriorated: he looked ill, became restless, spoke aloud to himself, and began to eat pencils and to lick walls. On admission to hospital at 11 years he was underweight. The only abnormal neurological signs were contraction of the left visual field and incontinence of urine. His appearance was normal and his mental age was assessed at 7 years. His speech was drawling and echolalic. The condition was diagnosed as Schilder's disease. When 12 years old he was admitted to the Fountain Hospital. He was then very restless, and slow of speech, and the plantar responses were extensor. At 13 years he had a succession of fits, went rapidly downhill, and died from pneumonia.

\section{PATHOLOGICAL FINDINGS IN CASE 2}

No necropsy records of this case have been preserved and there were only some slides of the central nervous system, not all fully satisfactory.

Large demyelinated areas were present in both cerebral hemispheres, extending from the anterior extremity of the frontal lobes and involving all of the basal ganglia except the striate body, and a large part of the temporal and parietal lobes. Posteriorly, the lesions ended about a centimetre behind the insula. The white matter adjoining the lateral surface of the posterior horns of the lateral ventricles was also affected. The subarcuate myelin fibres were often but not invariably spared. Within the affected area most of the myelin sheaths had disappeared, although a few groups of preserved fibres bearing no relation to blood vessels could be identified on microscopical examination. The cellular character of the lesions and content of sudanophil material were as in case 1 above. 'Epithelioid' and globoid cells were also present.

The cerebral cortex showed greater neuronal loss than in case 1, especially in layer III of the frontal lobe. Elsewhere, nerve cells showed central chromatolysis. Slight neuronal loss was possibly also present in the hippocampus. The cerebellum showed some focal loss of Purkinje cells and rarefaction of the granular layer. Bergmann glia was hyperplastic. Some cellular loss was also present in the dentate nucleus. Many myelin fibres around the dentate nucleus were tortuous and ballooned but there was no perivascular cuffing in this area. The only available section of the pons showed moderate subependymal gliosis. The main descending bundles of white matter showed moderate pallor of myelin staining.
SUMMARY OF PREVIOUSLY REPORTED CASES

Case III 2 has been summarized by Stewart et al. (1927) as follows:

'W.W. Boy, aged 8. History first of deafness and mental apathy, then of blindness, hemiplegia, and finally complete helplessness, the illness lasting about 12 to 18 months. Brain lesion-a diffuse sclerosis of the white matter of the occipital and temporal lobes, leaving the cortex and subcortical white matter intact. This sclerosis is characterized by almost complete destruction of myelin sheaths and, to a slightly lesser degree, of axis cylinders, and by replacement of these by a dense neuroglial overgrowth. Numerous compound granular corpuscles and perivascular collections of mononuclear cells are found in the more recently diseased areas'.

In addition, globoid cells, as in the present cases, were also present. Greenfield (1958) considered that this case was, like case III 6 below, an instance of familial sudanophilic diffuse sclerosis or Schilder's disease.

Case III 6 was a boy who died aged 10 years. When 8 years old, he developed personality changes accompanied by dragging of the left foot. In the last months of life he lost sphincter control and practically all speech. The neuropathological findings were summarized by Meyer and Pilkington (1936) as follows. ' 1 Diffuse demyelination together with circumscribed lesions, resembling atypical patches of disseminated sclerosis. 2 Within the diffuse demyelination, persisting perivascular islands, which are regarded as breakdown stages of the islands known in the Pelizaeus-Merzbacher disease. 3 Few remnants of "concentric" structures.'

The authors observed: 'Our case is particularly interesting by reason of its transitional features. This supports the opinion of Hallervorden and Spatz (1957), who feel justified in considering that all the demyelinating diseases are pathogenically related. Attention is particularly attracted to the perivascular islands, which stand out in the complete degeneration of the white matter. Because of the ring-like wall, which takes on myelin stains, they simulate foci of concentric sclerosis. Yet no further "concentric" layers were detected except for rather scanty remnants in the most peripheral parts of the lesion immediately below the arcuate fibres. On the other hand, these islands are very like the perivascular myelin islands in Pelizaeus-Merzbacher disease. In fact, it is intriguing to regard them as a breakdown stage of such myelin islands, thus representing a transitional stage between diffuse sclerosis and Pelizaeus-Merzbacher disease.' The authors thought that their case was also an example of Schilder's disease. 
TABLE II

CASES REPORTED IN THE LITERATURE UNDER THE NAME OF PELIZAEUS-MERZBACHER DISEASE

No. Sex Age at Onset Duration $\quad \begin{aligned} & \text { Age when Described } \\ & \text { or when Dead }\end{aligned}$ Myelin Islands Sudanophil Breakdown
or when Dead ${ }^{1}$

Family described by Pelizaeus and Merzbacher (the first five cases were described by Pelizaeus (1885), the remaining nine by Merzbacher (1910, 1923); and case 10 also by Spielmeyer (1923), and by Liebers (1928).

$\begin{array}{lll}1 & \text { M } & 3 \mathrm{mth} . \\ 2 & \text { M } & 3 \mathrm{mth} . \\ 3 & \text { M } & \text { End of first } \\ 4 & \text { M } & \text { Birth } \\ 5 & \text { M } & \text { Birth } \\ 6 & \text { M } & 10 \text { wk. } \\ 7 & \text { M } & 3 \text { mth. } \\ 8 & \text { F } & 3 \text { mth. } \\ 9 & \text { M } & 3 \text { mth. } \\ 10 & \text { F } & 4-5 \text { mth. } \\ 11 & \text { M } & 3 \text { mth. } \\ 12 & \text { M } & \text { Birth } \\ 13 & \text { M } & 9 \text { wk. } \\ 14 & \text { M } & 3 \text { mth. }\end{array}$

$\begin{array}{ll}33 \mathrm{yr} . & (33 \mathrm{yr} .) \\ 52 \mathrm{yr} . & 52 \mathrm{yr} . \\ 19 \mathrm{yr} . & 20 \mathrm{yr} . \\ 32 \mathrm{yr} . & 32 \mathrm{yr} . \\ 23 \mathrm{yr} . & 23 \mathrm{yr} . \\ 25 \mathrm{yr} . & (25 \mathrm{yr} .) \\ 20 \mathrm{yr} . & 20 \mathrm{yr} . \\ 26 \mathrm{yr} . & (26 \mathrm{yr} .) \\ 22 \mathrm{yr} . & (22 \mathrm{yr} .) \\ 28 \mathrm{yr} . & 28 \mathrm{yr} . \\ 6 \mathrm{yr} . & (6 \mathrm{yr} .) \\ 4 \mathrm{yr} . & (4 \mathrm{yr} .) \\ 2 \mathrm{yr} . & (2 \mathrm{yr} .3 \mathrm{mth} .) \\ 1 \mathrm{yr} . & (1 \mathrm{yr} .2 \mathrm{mth} .)\end{array}$
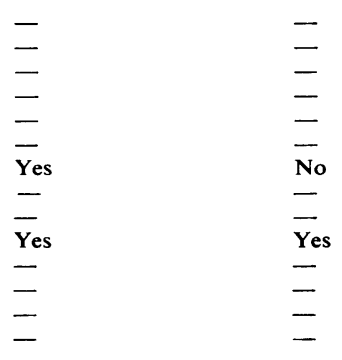

Müller (1907) 'Wurzburger Fall'

$$
\text { M 1-2 yr.(?) }
$$

15-16 yr.

$17 \mathrm{yr}$.

von Hagen and Sult (1939)

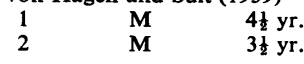

Camp and Löwenberg (1941)

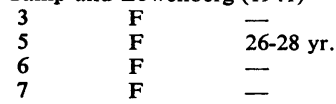

$4 \frac{1}{2} \mathrm{yr}$.

$1 \mathrm{yr}$.

9 yr.

$4 \frac{1}{2}$ yr.

$\overline{18-20} \mathrm{yr}$.

Middle 6th decade

Many years (?)

$56 \mathrm{yr}$.

-

$60 \mathrm{yr}$.

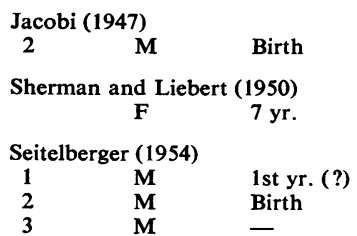

$5 \mathrm{yr}$.

$5 \mathrm{yr}$.

Yes

$15 \mathrm{mth}$.

$8 \frac{1}{2}$ yr.

Yes

$\begin{array}{ll}6-7 \mathrm{yr} . & 7 \mathrm{yr} .5 \mathrm{mth} . \\ 2 \mathrm{yr} .9 \mathrm{mth} . & 2 \mathrm{yr} .9 \mathrm{mth} .\end{array}$

- 1 yr. 3 mth.

Yes

Blackwood and Cumings (1954)

$$
3 \text { F 2-3 yr. (?) }
$$

10-12 yr.

$13 \mathrm{yr}$.

Yes

No

Family described by Bostroem (1927) and subsequently by Wicke (1938)

$\begin{array}{lll}\text { V 7 } & \text { M } & \text { 3 mth. } \\ \text { V 11 } & \text { M } & \text { 4-5 mth. } \\ \text { V 15 } & \text { M } & \text { 3-4 mth. } \\ \text { V 16 } & \text { M } & \text { 3-4 mth. } \\ \text { V 19 } & \text { M } & \text { End 1st yr. } \\ \text { V 20 } & \text { M } & \text { 3 mth. } \\ \text { V 21 } & \text { M } & \text { 3-4 mth. } \\ \text { V 24 } & \text { M } & \text { 3 mth. }\end{array}$

Bielschowsky and Henneberg (1928)

$$
\text { M } 6 \text { yr. }
$$

$\begin{array}{cc}21 \mathrm{yr} . & (21 \mathrm{yr} .) \\ 23 \mathrm{yr} . & (23 \mathrm{yr} .) \\ 18 \mathrm{yr} . & (18 \mathrm{yr} .) \\ 17 \mathrm{yr} . & (17 \mathrm{yr} .) \\ 24 \mathrm{yr} . & 25 \mathrm{yr} . \\ 7 \mathrm{yr} . & 7 \mathrm{yr} . \\ 9 \mathrm{yr} . & (9 \mathrm{yr} .) \\ 1 \mathrm{yr} .9 \mathrm{mth} . & 2 \mathrm{yr} .\end{array}$

Bodechtel (1929)

$\begin{array}{lll}1 & \mathrm{~F} & 5 \mathrm{yr} \\ 2 & \mathrm{~F} & 5 \mathrm{yr}\end{array}$

$15 \mathrm{yr}$.

Yes

Yes

Yes

Yes

(21 yr.)

18 yr.)

17 yr.)

7 yr.

$2 \mathrm{yr}$.

Löwenberg and Hill (1933)

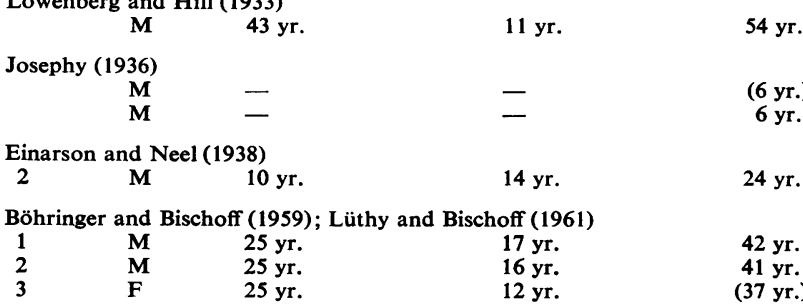

$16 \frac{1}{2} \mathrm{yr}$.

$5 \frac{1}{2} \mathrm{yr}$.

E

Yes

-

क 
Case IV 2, described by Norman (1961) was a boy who died at 12 years after some five years of illness, with mental disturbance and terminal motor deficit. The central nervous system showed sudanophilic leucodystrophy.

\section{DISCUSSION}

It is not intended to discuss here the many debatable issues arising out of the suggested revised classfications of conditions formerly grouped together as Schildet's disease or diffuse sclerosis (Poser and van Bogaert, 1956; Radermecker, 1957; Seitelberger, 1958). The findings in all five cases are basically similar and the diagnosis is fully compatible with what is now known as sudanophilic leucodystrophy.

In the past, the amount of perivascular cuffing found might have been regarded, by some workers, as evidence of the so-called 'inflammatory' form of Schilder's disease, but this distinction is no longer generally maintained. Varying amounts of perivascular cuffing are in keeping with sudanophilic leucodystrophy, and the only really infective condition which might have been formerly regarded as Schilder's disease is probably inclusion-body encephalitis.

However, Pelizaeus-Merzbacher disease has to be considered more carefully in classifying the present cases. This condition is usually differentiated from other forms of leucodystrophy by longer duration, sex-linked inheritance, and preservation of perivascular 'islands' of myelin in the devastated areas. The possibility of biochemical differentiation has also been mooted, but the criteria are not yet sufficiently precise (Blackwood and Cumings, 1954; Seitelberger, 1958).

The reported cases of Pelizaeus-Merzbacher disease are listed in Table II.

Many of the reported cases were, indeed, chronic, but some had run a more acute course. Moreover, the mandatory chronicity may have precluded otherwise similar, but more acute, cases from being reported as Pelizaeus-Merzbacher disease. Hence, the duration of four to six years in the present cases need not be inconsistent with this diagnosis.

Closer scrutiny of the recorded cases of PelizaeusMerzbacher disease shows that, contrary to frequently expressed views, the mode of inheritance is not uniform. In fact, although the condition was apparently transmitted as a sex-linked recessive for several generations in the original family described by Pelizaeus and by Merzbacher (Pelizaeus, 1885; Merzbacher, 1910), there were two affected female sibs in the last generation. The inheritance was thus consistent with dominance or partial dominance rather than sex-linked inheritance. This was also the view of Einarson, Neel, and Strömgren (1944). The incidence in the family recorded by Bostroem (1927) and by Wicke (1938) is compatible with sexlinked recessive inheritance, but there is no evidence of sex linkage in the pedigree reported by Camp and Löwenberg (1941) where the condition behaves as an autosomal dominant. The sibship described by Seitelberger (1954) contains three affected males in the last generation, the parents being unaffected. The inheritance here could be simple recessive. In another sibship recently reported by Böhringer and Bischoff (1959) and by Lüthy and Bischoff (1961) two males and one female were affected, the parents being phenotypically normal. Thus, the inheritance could have been autosomally recessive; there is no evidence of sex linkage. As with the duration, a diagnostic criterion of sex-linked inheritance might have prevented more, otherwise acceptable, cases in females from being classified or reported as PelizaeusMerzbacher disease. The inheritance in the present cases is in keeping with sex-linked recessive transmission.

The histologically demonstrable preservation of islands of myelin in some cases of PelizaeusMerzbacher disease might be regarded as evidence of a relatively slow and intermittent progression. However, it is not specific and may occur in other conditions. Thus, it was recently recorded in a case of central neurofibromatosis (Crome, 1962). In the present series, preservation of myelin islands was absent in four, and possibly present in one, of the cases.

It thus appears that none of the diagnostic criteria of Pelizaeus-Merzbacher disease is invariable or pathognomonic, and that the condition could easily be confused with other, more chronic, instances of leucodystrophy. The present cases show several features of such transition or overlap. The occurrence of globoid cells in at least three of the present cases adds further difficulty to problems of classification, since these are held by some workers to be characteristic of yet another form of leucodystrophyKrabbe's leucodystrophy.

The above comments indicate that current views on the classification of leucodystrophy are not entirely satisfactory.

\section{SUMMARY}

Five cases of sudanophilic leucodystrophy occurred in one English family, and all have had full neuropathological examination. Three had been recorded previously and the remaining two are presented for the first time in this communication. The transmission is compatible with sex-linked inheritance. The clinical, pathological, neurochemical, and 
genetical features are quite characteristic of sudanophilic leucodystrophy, although there is also some resemblance to Pelizaeus-Merzbacher disease and to Krabbe's leucodystrophy. It is suggested that the present classification of the leucodystrophies is not entirely satisfactory.

We are greatly indebted to many colleagues at the Fountain and Queen Mary's Hospitals for their advice in the preparation of this report and for access to case records. We are particularly grateful to Dr. Lawson for permission to quote the clinical findings in case 1 . Dr. Valerie Cowie has helped us greatly with the genetical studies of recorded cases of Pelizaeus-Merzbacher disease. Professor J. N. Cumings has kindly prepared the data in Table I. Many colleagues have read and commented upon the manuscript.

\section{BIBLIOGRAPHY}

Bielschowsky, M., and Henneberg, R. (1928). J. Psychol. Neurol. (Lpz.), 36, 131.

Blackwood, W., and Cumings, J. N. (1954). J. Neurol. Neurosurg. Psychiat., 17, 33.

Bodechtel, G. (1929). Z. ges. Neurol. Pschyiat., 121, 487.

Böhringer, H. R., and Bischoff, A. (1959). Ophtalmologica (Basel), $137,147$.

Bostroem, A. (1927). Dtsch. Z. Nervenheilk., 100, 63.
Camp, C. D., and Löwenberg, K. (1941). Arch. Neurol. Psychiat. (Chicago), 45, 261.

Crome, L. (1962). Arch. Dis. Childh., 37, 640.

Cumings, J. N. (1962). Personal communication.

Einarson, L., and Neel, A. V. (1938). Acta Jutland, 10, 1-160.

$\longrightarrow$ Neel, A., and Strömgren, E. (1944). Ibid., 16, 1-178.

Greenfield, J. G. (1958). In Neuropathology, edited by J. G. Greenfield, p. 441. Arnold, London.

Jacobi, M. (1947). Virchows Arch. path. Anat., 314, 460.

Josephy, H. (1936). In Handbuch der Neurologie, edited by O. Bumke and 0 . Foerster, vol. 16, p. 887. Springer, Berlin.

Liebers, M. (1928). Z. ges. Neurol. Psychiat., 115, 487.

Löwenberg, K., and Hill, T. S. (1933). Arch. Neurol. Psychiat. (Chicago), 29, 1232.

Lüthy, F., and Bischoff, A. (1961). Acta neuropath. (Berl.), 1, 113. Merzbacher, L. (1910). Z. ges. Neurol. Psychiat., 3, 1.

- (1923). Zbl. ges. Neurol. Psychiat., 32, 202.

Meyer, A., and Pilkington, F. (1936). J. ment. Sci., 82, 812.

Müller, E. (1907). Inaug. Diss., Würzburg. Cited by Merzbacher, L. 1910.

Norman, R. M. (1961). Personal communication.

Pelizaeus, F. (1885). Arch. Psychiat. Nervenkr., 16, 698.

Poser, C. M., and van Bogaert, L. (1956). Acta psychiat. (Kbh.) $31,285$.

Radermecker, J. (1957). Acta neurol. belg., 57, 498.

Seitelberger, F. (1954). Wien. Z. Nervenheilk., 9, 228.

(1958). Ibid., 14, 74.

Spielmeyer, W. (1923). Zbl. ges. Neurol. Psychiat., 32, 203.

Sherman, I. C., and Liebert, E. (1950). Arch. Neurol. Psychiat. (Chic.), $63,329$.

Stewart, T. G., Greenfield, J. G., and Blandy, M. A. (1927). Brain, $50,1$.

Wicke, R. (1938). Z. ges. Neurol. Psychiat., 162, 741.

von Hagen, K. O., and Sult, C. W. (1939). Bull. Los Angeles neurol D Soc., 4, 23. 